http://jmscr.igmpublication.org/home/ ISSN (e)-2347-176x ISSN (p) 2455-0450 crossref DOI: https://dx.doi.org/10.18535/jmscr/v9i1.40

\title{
A Study on Prevalence of severity of Depressive disorders in female spouses of Alcohol Dependence Patients
}

Authors

Dr Aravindh. $\mathbf{M}^{1}$, Dr Asok Kumar. $\mathbf{M}^{2}$, Dr Gandhibabu. $\mathbf{R}^{3}$

${ }^{1}$ Postgraduate, Department of Psychiatry, Rajah Muthiah Medical College and Hospital, Annamalai

University, Chidambaram, Tamil Nadu

${ }^{2}$ Professor and Head, Department of Psychiatry, Rajah Muthiah Medical College and Hospital, Annamalai University, Chidambaram, Tamil Nadu

${ }^{3}$ Professor, Department of Psychiatry, Rajah Muthiah Medical College and Hospital, Annamalai University, Chidambaram, Tamil Nadu

\begin{abstract}
Background: Alcoholism is the major drug abuse in India that affects spouses of the men with Alcohol dependence disorders had a higher rate of sexual problems, mental health problems and also physical health problems. These women also had suicidal thoughts, attempted suicide, minority and had short marriage life. Hence, a study with 200 female spouses of alcoholic husbands attending Rajah Muthiah Medical College and Hospital were assessed.

Results: Among the female spouses $25 \%$ participants had moderate depression and $24 \%$ had severe depression. Among the participants with no, mild, moderate and severe depression, 3.4\%, 23.3\%, 36\% and $70.8 \%$ had suicidal ideation. Presence of depression was found to be associated with that of suicidal ideation with $p$ value less than 0.05 .

Conclusion: In this study, the prevalence of depression among Spouses of Alcohol patients was high. This may have its own impact on the treatment outcome and prognosis of patients with mental illness and might even lead to suicide of the spouse. Depression among female spouses was associated with low perceived social support and the patient's psychiatric symptoms.

Keywords: Suicidal ideation, abuse, mental illness.
\end{abstract}

\section{Introduction}

The Alcohol use related disorders magnitude in developing country like India which has the second largest population in the world out of which $33 \%$ of its population consuming alcohol ${ }^{2,3}$. According to Lancet's Global Disease Burden Study, 2010, " 4.9 million people die and $5.5 \%$ of total DALYs losses worldwide are linked to problematic alcohol use" 4 .
In the year 2014, World Health Organization Global Status Report on alcohol and health states that "3.3 million people die annually because of increase in alcohol dependence" . It is one of the leading cause of deaths in the productive groups of age around 15-49 as stated by Lim, Stephen S et al, 2013. About one third of the population in India suffers from extreme poverty as they consume alcohol extensively as stated by the 
author Saxena, Shekhar, Raj Sharma, and Maulik, 2003.

The latest trends in alcohol intake are alarming, as the mean age of first drink dropped from 28 years to 17 years between 1980 and 2007. Lewis et al ,1983 have shown that the masculine gender; antisocial personality and family history of alcoholism increases the risk of alcoholism ${ }^{4}$.

Psychological literature when moved retrospectively shows the effects of alcoholism on 'significant others' on alcoholics has highlighted the amount of stress and burden suffered by those in the social network of heavy drinkers and especially by the inmate female partners ${ }^{5}$. The alcoholic dependence husbands are so addicted with drinking that they ignore the needs and circumstances of other family members, especially female spouses and is unable to assume the expected quality roles and responsibilities. In such scenario, those functions and care which were normally carried out by husbands often fall on their wives respectively that further add on to their burden and suffering 6,7 .

In the series of studies in India, Stanley found that wives of alcohol dependence partners had higher level of pessimism, neuroticism, conflict and perceived more danger than the control group ${ }^{8}$.

Although anecdotal cases indicate the possible link between drug use and mental disorders in the married women of alcohol dependence husbands, it should be noted that psychiatric problems are not limited to drug users, and may also affect their other family members as well ${ }^{9}$. In the initial phases of life, it often occurs when the abuser is under the influence of alcohol, and gradually it forms an conditioned response.

Nemeth et al in his study examined the causes of high levels of violence among married women to alcoholic husband through telephone interview sessions ${ }^{10}$. They found that "accusations of infidelity in the form of alcohol or drug use were the most common causes". Although in a recent study, a very small percentage of married women reported being an affected lady of violence; moreover, in past studies shown that the prevalence of violence among the married women of alcoholic husbands is high which in turn leads to depressive disorders. In a set of studies reported violence in a particular domain groups like emotional, physical, economic and intellectual that might lead to depression and at last ends in suicide due to poor mental care ${ }^{11}$.

Studies using cross sectional and longitudinal designs have primarily focused on alcohol -use disorder (AUDs) diagnoses to demonstrate that spouses of individuals with AUDs report higher rates of physical and psychological distress as well as lower levels of marital satisfaction and more frequent reports of emotional and physical violence $^{13}$.

Both psychological and physical violence done by the addicted husband were found to be major risk factors of household food insecurity (HFI). Psychological violence was more straight forwardly linked with HFI that is indirectly through physical violence and Common Mental Disorders (CMD), and directly in an unknown way. The results of physical violence seemed to be exclusively through $\mathrm{CMD}^{12}$ out of which most common mental disorder is depressive disorders.

Married women of alcoholic men had a higher rate of physical abuse, sexual abuse and other psychiatric health problems. These female spouses were at the edge of getting suicidal thoughts, attempting suicide, more commonly younger females were involved and had very short marriage life span ${ }^{14}$. With the researched literature, physicians usually focus on alcoholic men only and leaving behind the family members mainly inmate partner. Consequently, this ends up in neglecting the family members mental issues that in turn leads to depression, physical health disorders and suicide ${ }^{15}$.

Out of 157 suicide attempters in a study were the female spouses of alcoholic husbands were taken history and examined with the help of a selfinnovated proforma that was designed to know the major cause for their suicidal attempts. These subjects were selected from the ICU Unit of Stanley Government Hospital, Chennai. Some of 
their personal problems and family stressors were taken into considerations which made them to behave harshly which resulted in the histories, such as disturbed relation with their own relatives, financial problems, being harshly handled by their husbands and reduction in emotional support , which were different from those records noted in other reports on suicide attempts ${ }^{16}$. India has the higher suicide death rates in the world. A larger amount of people commits suicides occur at younger ages, especially in women ${ }^{18}$.

Studies in low- and middle-income countries (LMICs) like India had been found sex as a disadvantage and lack of autonomy that moves the married women towards higher risk of intimate partner violence ${ }^{19,20}$ as well as suicide. Other factors like poverty, limited financial resources, lack of economic activities and social resources also has a potential risk for poor psychological health of women particularly in low and middle income countries ${ }^{17}$.

In a study conducted in Iceland resulted in about $36 \%$ or more of sample population affected with higher degree of depression, anxiety and stress due to the Substance abuse disorder in family members which is higher than the Depression, anxiety and stress from substance abuse disorders (DASS) studies of general population in Iceland ${ }^{21}$. In a population-based study it has been found that a little, but has a significant impact on married women of male at-risk drinkers to end up in more psychological distress than married women of controls ${ }^{23}$. Another study done by Ragnmo et al found that three times higher risk depressive disorders in married women of alcoholic husbands ${ }^{22}$.

\section{Setting}

The study will be conducted among patients and their female spouse attending Psychiatry Outpatient Department Rajah Muthiah Medical College Annamalai University, Annamalai Nagar, Chidambaram.

\section{Sample}

Two hundred patients and their female spouses were consecutively selected who are attending Psychiatry Outpatient department, Rajah Muthiah medical college, Annamalai university, Annamalai Nagar, Chidambaram.

\section{Study Design}

Observational study - Cross sectional study

\section{Inclusion Criteria}

- Female spouses of all age group.

\section{Exclusion Criteria}

- Female spouses with acute physical illness, known case of psychiatric illness and on any psychotropic medication are excluded.

- Female spouses not consenting for the study

\section{Interview}

Female spouses of Patients with diagnosis of Alcohol dependence syndrome who are attending Psychiatry Outpatient Department Rajah Muthiah Medical College, Annamalai University will be selected. The nature of the study and its objectives will be explained to the female spouses. A written informed consent will be obtained from the female spouses. The assessment will be conducted in single session lasting for an hour.

\section{Materials Used}

1. Self-innovated proforma to elicit the Socio Demographic data of the female spouses and the years of association with the patient.

2. Hamilton Rating Scale for Depression (HAM-D)

3. ICD - 10 Criteria for classification of mental and behavioral disorders

\section{Results}

Table 1: Distribution of study participants according to HAM - D score

\begin{tabular}{|l|c|c|}
\hline HAM D score & Frequency & Percent \\
\hline$\leq 5$ & 12 & 6.0 \\
\hline $6-10$. & 53 & 26.5 \\
\hline $11-15$. & 49 & 24.5 \\
\hline $16-20$ & 70 & 35.0 \\
\hline $21-25$ & 6 & 3.0 \\
\hline$>25$ & 10 & 5.0 \\
\hline Total & 200 & 100.0 \\
\hline
\end{tabular}




\section{JMSCR Vol||09||Issue||01||Page 208-215||January}

Fig 1: Bar chart showing distribution according to HAM D scores

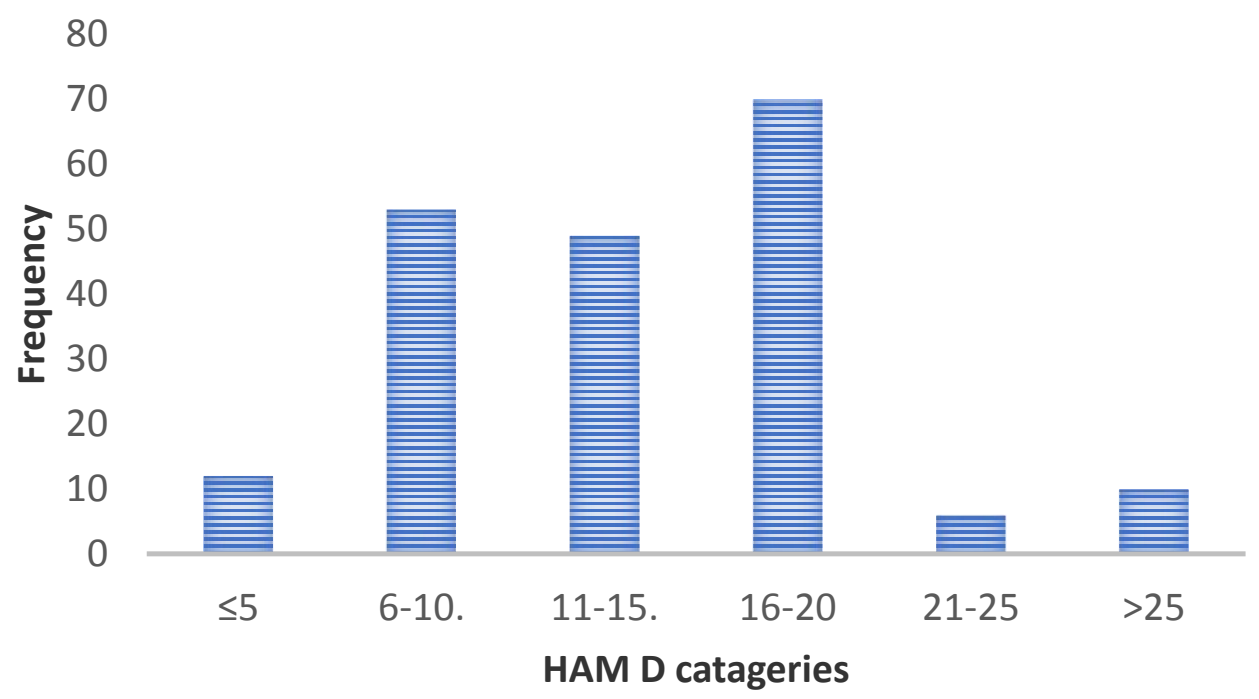

$35 \%$ had HAM D score between 16 and 20 followed by $26.5 \%$ between 6 and 10 . The mean HAM D score was $13.71 \pm 5.94$.

Table 2: Distribution according to depression grade

\begin{tabular}{|l|c|c|}
\hline Depression grade & Frequency & Percent \\
\hline Nil & 59 & 29.5 \\
\hline Mild & 43 & 21.5 \\
\hline Moderate & 50 & 25.0 \\
\hline Severe & 48 & 24.0 \\
\hline Total & 200 & 100.0 \\
\hline
\end{tabular}

Fig 2: Bar chart showing distribution according to depression grade

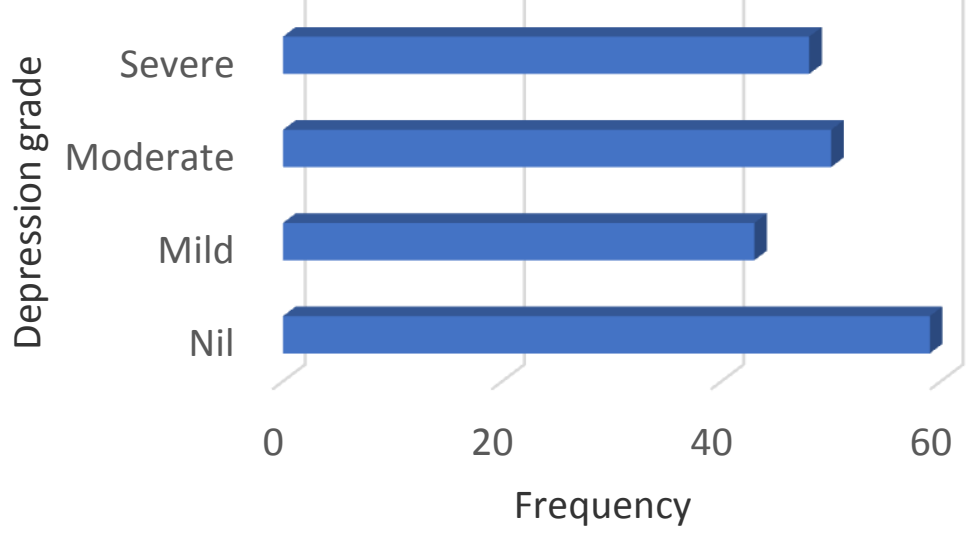

$25 \%$ participants had moderate depression and $24 \%$ had severe depression. 


\section{JMSCR Vol||09||Issue||01||Page 208-215||January}

Table 3: Distribution of depression among the study participants in a pie chart

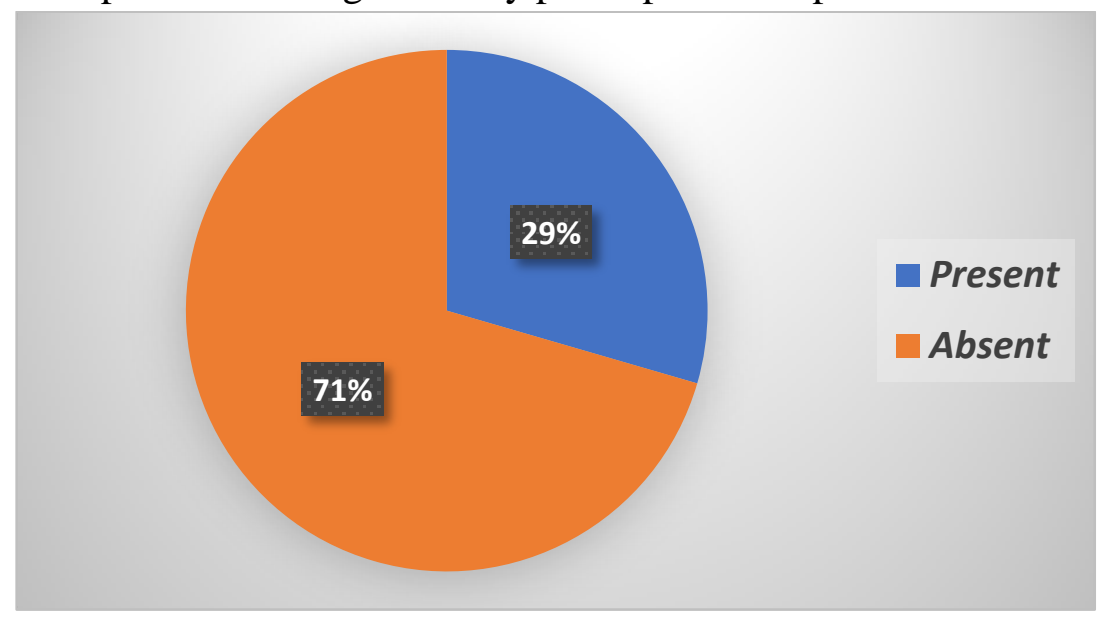

Shows about $71 \%$ of the study participants are affected due to depression.

Table 3: Association between depression grading and suicidal ideation

\begin{tabular}{|c|c|c|c|c|c|c|c|c|}
\hline \multirow{3}{*}{ Suicidal ideation } & \multicolumn{8}{|c|}{ Depression grade } \\
\hline & \multicolumn{2}{|c|}{ Nil } & \multicolumn{2}{|c|}{ Mild } & \multicolumn{2}{|c|}{ Moderate } & \multicolumn{2}{|c|}{ Severe } \\
\hline & $\mathbf{N}$ & $\%$ & $\mathbf{N}$ & $\%$ & $\mathbf{N}$ & $\%$ & $\mathbf{N}$ & $\%$ \\
\hline Present & 2 & 3.4 & 10 & 23.3 & 18 & 36.0 & 34 & 70.8 \\
\hline Absent & 57 & 96.6 & 33 & 76.7 & 32 & 64.0 & 14 & 29.2 \\
\hline Total & 59 & 29.5 & 43 & 21.5 & 50 & 25.0 & 48 & 24.0 \\
\hline
\end{tabular}

Fig 4: Compound bar chart showing distribution of depression grade with respect to suicidal ideation

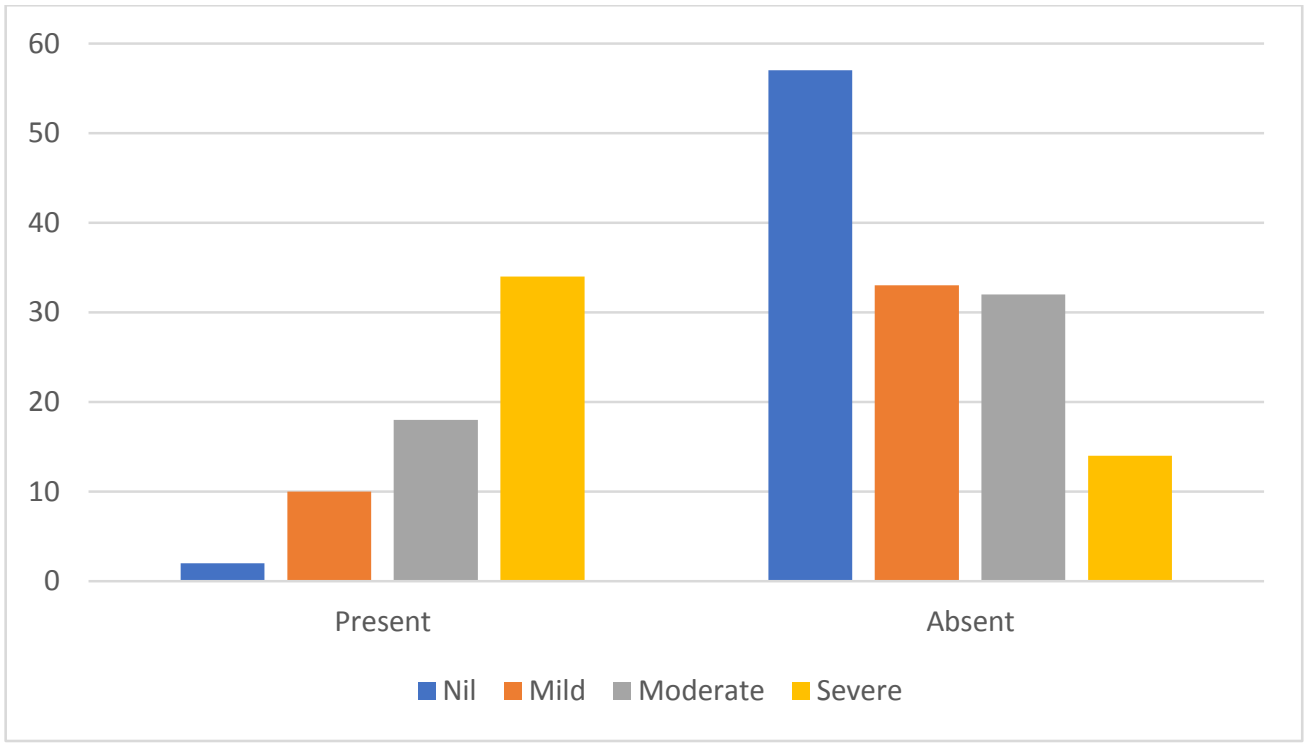

Among the participants with no, mild, moderate and severe depression, $3.4 \%, 23.3 \%, 36 \%$ and $70.8 \%$ had suicidal ideation. Presence of depression was found to be associated with that of suicidal ideation with $\mathrm{p}$ value less than 0.05 .

\section{Discussion}

Spouses of alcohol dependence husband usually faces many number of physical violence and threats of violence, sexual and emotional abuse, lack of trusting relations, social isolation due to financial burden, humiliation, chronic mental or physical problems ${ }^{24}$ (e.g. depression) .As this study involves 200 female spouses of alcohol dependence husband were assessed with HAM D Rating Scale that showed less than 5 score for $12(6 \%)$ female spouses, $6-10$ score for $53(26.5 \%)$ female spouses, $11-15$ score for 49 
(24.5\%) female spouses, 16 -20 score for 70 (35\%) female spouses, $21-25$ score for $6(3 \%)$ female spouses and more than 25 score for 10 (5\%) female spouses resulting in the HAM -D score mean of $13.71=$ or -5.94 .

Out of 200 female spouses of alcoholic husbands 59 (29.5\%) female spouses showed no depression , $43(21.5 \%)$ female spouses showed mild severity of depressive disorder, 50 (25\%) female spouses showed moderate severity of depressive disorders and 48 (24\%) female spouses showed severe degree of depressive disorders more commonly occurred due to "marital dissatisfaction that could lead to psychiatric distress, and leads to the risk of inducing depressive disorders which in unhappily married women is $\sim 25$ times than that in happily married women ${ }^{25}$ which in turn lead to suicidal ideation.

If a compound bar chart is plotted for showing the suicidal ideation in depression it shows about 2 (3.4\%) female spouses had suicidal ideation without any form of depression, 10 (23.3\%) female spouses had suicidal ideation with mild degree of depression , 18 (36\%) female spouses had suicidal ideation with moderate level of depression and $34(70.8 \%)$ female spouses had suicidal ideation with severe degree of depression and some number of female spouses had attempted suicide once in their lifetime .Around $32 \%$ of female spouses had suicidal ideation in total after the assessment.

Hence, presence of depression is found to be well linked with that of suicidal ideation with $\mathrm{p}$ value less than 0.05 . This study concludes by showing a strong association between alcoholic husband and their spousal depression and suicidal ideations for various reasons as described above, hence proper assessment and care should be provided not only to the alcoholic patients but also to their inmate partners.

\section{Conclusion}

In this study, the prevalence of depression among Spouses of Alcohol patients was high. This may have its own impact on the treatment outcome and prognosis of patients with mental illness and might even lead to suicide of the spouse. Depression among female spouses was associated with low perceived social support and the patient's psychiatric symptoms. Therefore, while caring for patients, screening spouses of alcoholic patients and treating them accordingly, is crucial to decrease the incidence of depression. Significant proportions of the female spouses of alcoholic patients were suffering from psychiatric disorders that did not get any psychiatric treatment. So, the service providers, policymakers and planners should address the issues carefully, so that they could get proper psychiatric services. An in-depth study is recommended in this regard.

\section{Limitations}

Our study had some limitations. First, the study was limited by its cross-sectional design; we did not perform a follow-up assessment regarding changes in depression status. Our study did compare only with the female spouses with their alcoholic partners, not with the other family members nor with the general population. The cost of treatment for the patient with relation to psychiatric morbidity of female spouses not done in this study. Axis II disorders, in particular type A personality was not studied. It is a limitation considering the fact that type $\mathrm{A}$ is more often associated with depression.

\section{References}

1. Global Status Report on Alcohol. Geneva: 2004. [Last accessed on 2010 September 20]. World Health Organization (WHO) http://www.who.int/substance abuse/publications/ globalstatusreportalcohol2004_alcconsum pt.pdf.

2. Gururaj G, Girish N, Benegal V. New Delhi: Regional Office for South-East Asia; 2006. Burden and Socio-Economic Impact of Alcohol-Bangalore Study.

3. Ray R. The Extent, Pattern and Trends of Drug Abuse in India: National Survey. 
Ministry of Social Justice and Empowerment and United Nations Office on Drugs and Crime. 2004

4. Palaniappan H, James AGW, Annamalai A. Correlation between severity of alcohol dependence with age of onset and family history among urban alcoholics: a crosssectional study. J. Evolution Med. Dent. Sci. 2016;5 (52):3452-3457, DOI: 10.14260/jemds/2016/796.

5. Callinan S, Rankin G, Room R, Stanesby O, Rao G, Waleewong O, Greenfield TK, Hope A, Laslett AM. Harms from a partner's drinking: an international study on adverse effects and reduced quality of life for women. Am J Drug Alcohol Abuse. 2019;45(2):170-178. doi: 10.1080/00952990.2018.1540632. Epub 2018 Nov 29. PMID: 30495983; PMCID: PMC6478171.

6. Sharma, N., Sharma, S., Ghai, S., Basu, D., Kumari, D., Singh, D., \& Kaur, G. (2016). Living with an alcoholic partner: Problems faced and coping strategies used by wives of alcoholic clients. Industrial psychiatry journal, 25(1), 65-71. https://doi.org/10.4103/0972-6748.196053

7. Kaur D, Ajinkya S. Psychological impact of adult alcoholism on spouses and children. Med J Dr Patil Univ. 2014; 7:124.

8. Pradeep R Johnson, Carl Britto, Kevin Jude Sudevan, Ashish Bosco, Priya Sreedaran and Mysore V Ashok. Resilience in Wives of persons with Alcoholism:An Indian exploration. Indian J Psychiatry, 2018 Jan-Mar;60(1):84-89. PMID: 29736068

9. Noori, R., Jafari, F., Moazen, B., Khoddami Vishteh, H. R., Farhoudian, A., Narenjiha, H., \& Rafiey, H. (2015). Evaluation of anxiety and depression among female spouses of Iranian male drug dependents. International journal of high-risk behaviors \& addiction, 4(1), e21624.

10. Nemeth JM, Bonomi AE, Lee MA, Ludwin JM. Sexual infidelity as trigger for intimate partner violence. $\mathrm{J}$ Womens Health. 2012;2: 942-9. [PubMed] [Google Scholar]

11. Govindappa L, Pnkajakshi B. A community study on wives of alcoholics. [Last retrieved on 2015 Mar 30]; DPS. 2014 17:323-27.

12. Moraes CL, Marques ES, Reichenheim ME, Ferreira MF, Salles-Costa R. Intimate partner violence, common mental disorders and household food insecurity: an analysis using path analysis. Public Health Nutr. 2016 Nov;19(16):2965-2974. doi: 10.1017/S1368980016001178. Epub 2016 May 23. PMID: 27211890.

13. Lindsey M.Rodriguez,Ph.D. and Clayton Neighbors,Ph.D. An Interdependent look at Perceptions of Spousal Drinking Problems and Marital Outcomes. Alcohol. Author manuscript; available in PMC 2016 Sep 1. published online 2015 May 28. Doi:10.1016/j. alcohol.2015.05.002. PMID:26091752.

14. Juibari, T. A., Behrouz, B., Attaie, M., Farnia, V., Golshani, S., Moradi, M., \& Alikhani, M. (2018). Characteristics and Correlates of Psychiatric Problems in Wives of Men with Substance-related Disorders, Kermanshah, Iran. Oman medical journal, 33(6), 512-519. https://doi.org/10.5001/omj.2018.93

15. Noori R, Rafiey H, Azizabadi-Farahani M, Khoddami-Vishteh HR, Mirabi P, Farhadi $\mathrm{MH}$, Narenjiha H. Risk factors of suicidal ideation and attempt in women with drug user spouses. J Chin Med Assoc. 2013 Nov;76(11):648-52. doi: 10.1016/j.jcma.2013.07.003. Epub 2013 Aug 12. Erratum in: J Chin Med Assoc. 2013 Dec;76(12):727. PMID: 23938148. 
16. Ponnudurai, R., Uma, T. S., Rajarathinam, S., \& Krishnan, V. S. (2001). Determinants of suicidal attempts of wives of substance abusers. Indian journal of psychiatry, 43(3), 230-234.

17. Gupta, A., Priya, B., Williams, J., Sharma, M., Gupta, R., Jha, D. K., Ebrahim, S., \& Dhillon, P. K. (2015). Intra-household evaluations of alcohol abuse in men with depression and suicide in women: A crosssectional community-based study in Chennai, India. BMC public health, 15, 636. https://doi.org/10.1186/s12889-0151864-5

18. Patel V, Ramasundarahettige C, Vijayakumar L, Thakur JS, Gajalakshmi V, Gururaj G, et al. Suicide mortality in India: a nationally representative survey. Lancet. 2012;379(9834):2343-51. doi: 10.1016/S0140-6736(12)60606-0.

19. Patel V, Kirkwood BR, Pednekar S, et al. Gender disadvantage and reproductive health risk factors for common mental disorders in women: a community survey in India. Arch Gen Psychiatry. 2006;63: 404-13. doi: 10.1001/archpsyc.63.4.404.

20. Kumar S, Jeyaseelan L, Suresh S, Ahuja RC. Domestic violence and its mental health correlates in Indian women. $\mathrm{Br} \mathrm{J}$ Psychiatry. 2005; 187:62-7. doi: 10.1192/bjp.187.1.62.

21. Ólafsdóttir J, Hrafnsdóttir S, Orjasniemi T. Depression, anxiety, and stress from substance-use disorder among family members in Iceland. Nordisk Alkohol Nark. 2018 Jun;35(3):165-178. doi: 10.1177/1455072518766129. Epub 2018 May 29. PMID: 32934525; PMCID: PMC7434153.
22. Rognmo, K., Torvik, F. A., Røysamb, E., \& Tambs, K. (2013). Alcohol use and spousal mental distress in a population sample: the Nord-Trøndelag Health Study. BMC public health, 13, 319. https://doi.org/10.1186/1471-2458-13-319

23. Tempier R, Boyer R, Lambert J, Mosier K, Duncan CR. Psychological distress among female spouses of male at risk drinkers. Alcohol. 2006; 40:41-49. doi: 10.1016/j.alcohol.2006.09.032. [PubMed] [CrossRef] [Google Scholar]

24. Halford WK, Bouma R, Kelly A, et al. (1999) Individual psychopathology and marital distress. Behav Modif 23:179-216.

25. Weissman MM. (1987) Advances in psychiatric epidemiology: rates and risks for major depression. Am J Public Health 77:445-51. 